\title{
Working With Avatars and High Schoolers to Teach Qualitative Methods to Undergraduates
}

\author{
Kristin M. Murphy
}

\begin{abstract}
Learning to conduct qualitative research is a complex endeavor. In this article, I introduce mixed reality simulations as a scaffolded learning tool to support student mastery of learning and knowing how to conduct qualitative research. Like flight simulators used to train airline pilots prior to flying an actual airplane, mixed reality simulations provide active practice opportunities to interact with avatars in order to practice newly learned skills. I discuss this in the context of my experiences using mixed reality in an undergraduate youth participatory action research methods course as a scaffold before joining research teams with high-school-aged coresearchers.
\end{abstract}

\section{Background}

Immersive community-based learning is a transformative experience for teachers and students alike. Immersive learning takes students on a journey beyond textbooks and lectures, and brings course concepts to life through community-based active learning and problem solving centered around collaboration and critical thinking (Latz, Phelps-Ward, Royer, \& Peters, 2015). During the spring and fall 2016 semesters, I received funding to support the design, implementation, and evaluation of a course at my university that featured community-based immersive learning. I designed and taught a qualitative research seminar about youth participatory action research (YPAR) methods to junior and senior undergraduate students. In addition to learning about the foundations of qualitative research, students were responsible for working alongside high school students from a local urban school district on research teams and carrying out a full YPAR project. The immersive benefits were in play for the high school students as well. They participated in carrying out a full research project over the course of seven weeks with college students. For many of the students, it was their first time on a college campus, and my intention was to cultivate a positive experience in which the high school students experienced success and enjoyment conducting research at the college level, and for the students to receive mentorship from their college research partners.

In the course, students learned the foundations of, and went through the process of, conducting a credible and trustworthy qualitative youth participatory action research study alongside high school students from a local urban public school district serving as their coresearchers. Research teams utilized photovoice as their research method to explore the notion of how teenagers reported understanding their experiences at school and in their communities. Based on their findings, the research teams were tasked with making recommendations for the future. The ultimate goal was to empower the high school student coresearchers 
to communicate experiences and recommendations to peers, teachers, and school- and district-level leadership about what was working well and what needed to be improved upon. The course objectives for my college students were to (a) learn the ethics of qualitative research; (b) carry out a full photovoice research project in the context of a youth participatory action research methods project; (c) conceptualize, conduct, and report on a credible and trustworthy qualitative research photovoice study; (d) work alongside high school students as coresearchers on research teams; (e) coauthor a full research paper based on their project; and (f) construct and present a gallery-based exhibit of their photovoice work.

When I initially designed the course, I focused a lot of energy on the actual meetings my college students would have with their high school coresearchers, and the culminating gallery event at the end of the semester. I did not give as much thought to the actual experience of being a college student learning about qualitative research methods, and learning to lead an interview or focus group with high school students. Faced with teaching my first qualitative research methods course, I simply envisioned that my students would learn the same way I did.

Through discussion board responses and conversations that occurred in the early weeks of the semester, I was quickly reminded of a humble truth. Interviewing is a hard and oftentimes unpredictable endeavor. There are many approaches to interviewing as a research method, and the actual event itself can go in directions we did not imagine, despite our best intended plans (Roulston, deMarrais, \& Lewis, 2003). This was foreign territory for my class, consisting primarily of students from the hard sciences and coming to me with years of quantitative experience. Prior to beginning work with the high school students, it became clear that my undergraduates needed extensive preparation and varied practice opportunities to engage in qualitative research.

In this article, I hone in on my college students' journey of learning and knowing how to carry out qualitative research studies using photovoice methodology with high-school-aged coresearchers, and how my understanding of the context that would best support their learning and knowing shifted during the semester to include active practice opportunities with avatars in a mixed reality simulation environment. First, I will briefly discuss the literature on interviewing, YPAR, and photovoice. Then, I will introduce mixed reality simulations as a scaffolded tool for active learning and discuss in detail how I used it in my qualitative methods course. Next, I will present narrative findings of my college students' journey of learning and knowing about qualitative research from the start of the semester until after they completed mixed reality simulation exercises. Finally, I will conclude with lessons learned and recommendations for the future.

\section{Literature Review}

Interviews as research. Interviewing is a complex and oftentimes unpredictable endeavor. There is no single approach to interviewing as a research method (Roulston et al., 2003). Depending on the theoretical perspective you and your study follow and the focus of your study, the format of an interview can range from what Gubrium and Holstein (2002) refer to as a basic model or an active model. In the basic model, an interviewer's goal is to pull information from the interviewee while not infusing 
his or her own subjectivity or conversing about information considered extraneous to the study. In the newer active model, there is not one single truth as the interviewee and interviewer approach the interview as a collaborative partnership in reaching a new understanding about the research question (Gubrium \& Holstein).

Youth participatory action research. Youth participatory action research (YPAR) is a framework that seeks to empower youth as the resident expert and researcher of their own experiences, with the guidance and mentorship of adults who can support them as they engage in critical inquiry (Mirra, Garcia, \& Morrell, 2016). The voices of children, particularly children of color and from low-income communities, are markedly absent from the literature. Their perspectives are often dismissed, driven by the belief that they are too immature or unable to communicate their ideas appropriately (Brunson \& Miller, 2007). The consequence of this mindset is that youth are left feeling even more marginalized and believing that their opinions do not matter. When children and teenagers are invited to the table and asked to share their thoughts about the issues they face in their lives, the results can be transformative and empowering (Ginwright, 2007).

Photovoice as a YPAR method. One form of research that aligns well with the principles of YPAR is photovoice. Photovoice is an approach that integrates photography and critical discussion to examine issues from the perspective of "resident experts." Insights and findings are then used to inform social action. The goal is to promote change at the personal and community level, and to empower (Wang \& Burris, 1997; Wang, 2006). In today's day and age, we all take photographs. With the advent of smartphones, most of us have access to a high-quality camera for taking photographs and video in our pocket. We may carry thousands of our personal photographs and videos on our phone, and have access to even more via our social media accounts, also on our phones.

Photovoice is not bound specifically to YPAR, but certainly aligns well with its goals. Photovoice was first developed in the 1990s (Wang \& Burris, 1994) and is a common research tool used to engage in participatory research across health sciences, education, and beyond. Children and teenagers who may be traditionally viewed as participants and those who are to be researched, are instead our coresearchers, and are tasked with taking pictures that illuminate their experience with regards to the research question. The photographs then serve as an artifact to facilitate conversation and understanding about the topic at hand during interviews or focus groups. The addition of photographs adds a level of depth to the findings, and also lends itself to a different level of dissemination, access, and interaction with the findings than findings that may ultimately only end up in a research journal. Most photovoice studies culminate in a gallery event where community members and leaders can interact together with the goal of promoting change (Latz, 2017).

One of the most common ways to structure the interview or focus group in a photovoice study is the SHOWeD method (Wang \& Burris, 1997; Wang, 2006). The SHOWeD method consists of several structured discussion questions. After coresearchers take pictures in the field, they come together for a research team meeting. While looking at a picture, the group transitions through the following series of questions: (a) What do you see here?; (b) What's really happening here?; (c) How does this relate to our 
lives?; (d) Why does this situation exist?, or How can we become empowered through this?; and (e) What can we do about it?

The first question allows the participants to absorb and discuss all the dimensions of the photograph, from the obvious parts of the image to the small details in the background. In the second question, the participants begin to think critically and convey their thoughts regarding the situation present in the photograph. The third question leads the participants to reflect on how the photograph relates both to oneself and to their peers. In the fourth prompt, the participants hypothesize both the origins of this situation and the events that took place for this photograph to be relevant today. Finally, the last question prompts the group to envision community solutions related to the theme raised by the photograph (Wang \& Burris, 1997; Wang, 2006).

Conducting photovoice-driven YPAR work focuses on personal issues and experiences with the goal of promoting empowerment and change for the better in a community. Conducting an interview or focus group that may include conversation-sensitive topics, involves special care taken to ensure a positive, safe, and productive research experience for both the researcher and participant (Watts \& Liamputtong, 2013). Becoming an interviewer with this level of skill takes practice. Many qualitative researchers can remember back to their days as a student in qualitative methods courses and learning to interview by engaging in role-plays and practicing interviewing with their classmates.

Mixed reality simulations as a scaffolded learning tool. There is a long and varied collection of multidisciplinary research supporting role-play as an active learning opportunity as it can change behavior, attitudes, and knowledge as learners practice complex situations in a safe environment with their peers that presents little to no consequences (Storey \& Cox, 2015). However, in traditional roleplays where are all of the roles are played by fellow students, interpersonal issues can make the experience more difficult. A student can simplify things for another student in order to achieve social desirability, or conversely, can make a role-play too difficult. Furthermore, a student playing the interviewee may be disinterested altogether. Harnessing new technology like mixed reality simulations unleashes the potential to remove some of the interpersonal issues that may affect role-play or mock interview objectives (Murphy, Cash, \& Kellinger, 2018).

Mixed reality simulations (MRS) provide an opportunity for learners to practice what they are learning before applying concepts in the real world. It creates a risk-free environment for learners to safely take risks without harming real participants (Hughes, Nagendran, Dieker, Hynes, \& Welch, 2015). Like flight simulators used to train airline pilots prior to flying an actual airplane, MRS provides active practice opportunities to interact with avatars (i.e., computer-animated characters controlled by humans) in order to practice newly learned skills. MRS is an ideal tool to address the critical need for providing highimpact, low-risk preservice training. The body of research on MRS as a professional training tool is in its infancy, but there is a growing body of research exploring its use in preservice teacher coursework. Early MRS research in teacher preparation has shown that four 10-minute sessions yielded changes in teacher behavior that were translated into classroom practice (Straub, Dieker, Hynes, \& Hughes, 2014). 
MRS is a tool that require relatively little time, but may yield large benefits as a precursor and complement to fieldwork.

MRS offers a safe space to practice newly learned skills without the risk of harming students, clients, or patients (Murphy et al., 2018). MRS employs technology where avatars, displayed on a large monitor, spontaneously engage with participants by following a scenario protocol lasting approximately seven to 10 minutes. MRS can take place in environments spanning school, office, and health-based environments featuring children and adults for different scenarios and objectives. During the simulation, participants focus on a discrete skill and objective to accomplish. MRS follows what is known as the human-in-the-loop paradigm, where a human known as an Interactor actively controls the voices and movement of avatars, allowing for more authentic, spontaneous responses that reflect the nature of unpredictable human interactions (Hughes et al., 2015). The Interactor is a highly trained specialist that can see and hear the participants through a web camera and microphone, while the participants only see and hear the avatars displayed on the large monitor. One Interactor plays the role of all avatars involved in the MRS scenario, and controls all of their movements and voices. In addition to being versed in the objective of the scenario, Interactors are trained on how the avatars should respond based on the actions of the student participating in the simulation. There are "hits" and "misses" associated with achieving the objective. When a student engages in activities that lead up to, or achieve, the objective, he/she is engaging in hits, and the avatars act accordingly. Conversely, when the student engages in misses, or activities that deters him/her from achieving the objective, the avatars will respond accordingly and further derail from the desired objective.

The Interactor represents the defining characteristic that marks MRS as different from virtual reality environments. Since an Interactor actively controls the voices and movements of the avatars during a simulation, participating in an MRS can better replicate the unpredictable nature of human interactions (Hughes et al., 2015). This affords unique opportunities that would not be able to occur in a traditional college classroom lesson, and better mirrors fieldwork.

What does it look like to practice in a mixed reality environment? In the class I focus on in this paper, students engaged with avatars in an 8th grade classroom environment. There are five 8th grade student avatars seated in horseshoe style seating: Savannah, Dev, Ava, Jasmine, and Ethan (see Figure 1). The five student avatar profiles were developed in such a way that they are diverse enough in personality to represent the population across an entire classroom, even though the majority of classrooms comprise far more than five students. Their personalities stem from two major pairs of evidence-based personality factors: aggressiveness and passiveness, and independence and dependency. Their interactions with each other and the teacher provide for a multitude of challenges, opportunities, and teachable moments (Hughes et al., 2015). 


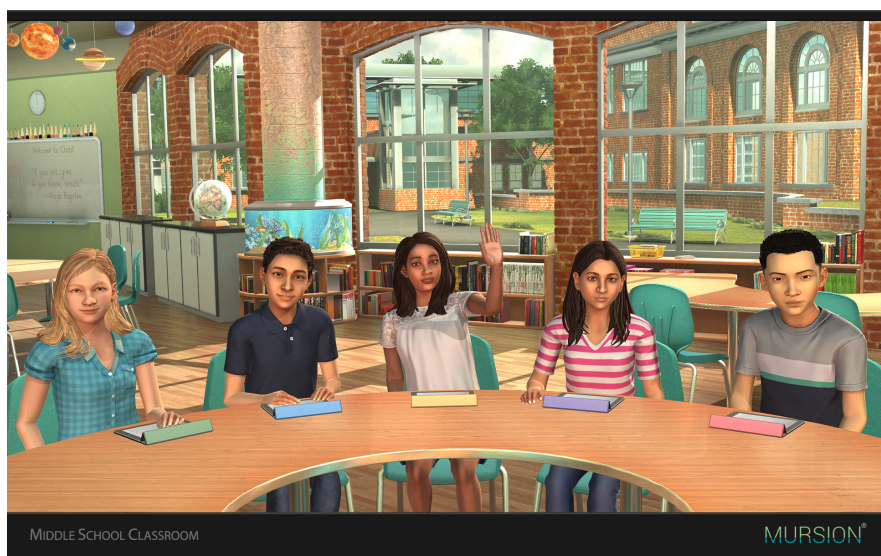

Fig. 1: Mixed reality simulation middle school classroom. Reprinted with permission by Mursion.

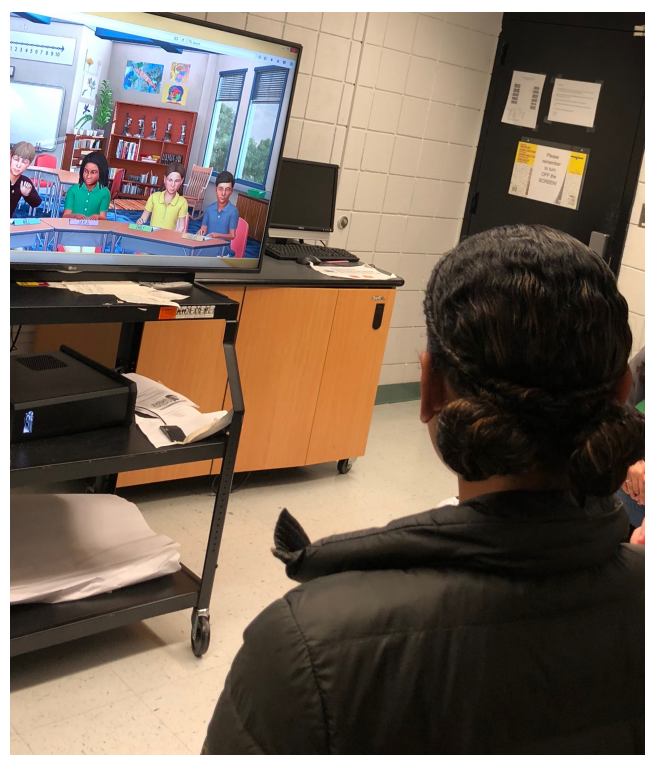

Fig. 2: A college student works with a 5th grade class of student avatars. Her peers and the professor are seated in a horseshoe around her to observe and provide coaching and feedback.

Students interact with the avatars by standing in front of a large screen monitor where they are displayed (see Figure 2). During simulations, the student is never alone with the avatars. Depending on the design of the course session, either an individual student or a team of students participate in a simulation, all while their peers and professor observe and take notes, seated in a horseshoe behind them so they may engage in observation. Before the simulation begins, the students are given a brief vignette that provides a jumping-off point for the simulation to begin. The Interactor can see the student through a web camera positioned on top of the monitor and hear them through a microphone set on the table, but the students can only see the avatars. Our students are instructed to stand in front of the monitor, and when they are ready, they say the magic words: "Start simulation." The classroom pops up on the screen, and students may begin to speak with the avatar(s) as if they are real students seated in front of them. As the interaction begins, our students engage in something known as a suspension of disbelief (Hayes, Straub, Dieker, Hughes, \& Hynes, 2013). This is a crucial component of the MRS experience. 
The students know that the simulation is not an actual middle school classroom. However, as they begin the simulation, they temporarily suspend the belief that it is not real, and instead accept it as reality. Time and time again, we witness our students, and ourselves, temporarily engage in this suspension of disbelief as we participate in simulations.

One of the most unique aspects of this type of practice is utilizing a feature I describe as "remote control teaching" (Murphy et al., 2018). At any given time during a simulation, the student or professor can "pause" the classroom if they need assistance from their peers or professor. They can then debrief with their peers and professor about what happened and receive on-the-spot coaching and feedback. Then, the classroom can be unpaused and a student can rehearse the exact same scenario again, either from where they left off, or start at the beginning again. This is also a way to scaffold the learning. In earlier coursework or early instances of practicing a new skill, students can be given the option of using the remote control. In later coursework or after practicing a skill multiple times, they may lose access to the remote control. Even without use of the remote control, time is set aside for a debrief after each simulation, one of the most crucial aspects of any MRS session. Students and the professor have the opportunity to give and receive coaching and feedback. While working with the avatars is a powerful experience in itself, I believe that the nature of the discourse that emerges during debrief sessions is truly one of the most unique, fruitful, and transformative aspects of incorporating MRS into coursework. Based on the debrief, students can then reflect on the experience and think about how they will improve upon it next time in a simulation and/or in fieldwork.

The application of MRS as a preservice teacher learning tool is becoming more widespread. Recent research indicates that four ten-minute mixed reality sessions resulted in improved teaching performance that transferred to live classroom teaching above and beyond traditional methods of teacher preparation (Straub et al., 2014). In the military, aviation, and medical fields, mixed reality simulations have utilized technology in training for decades (Barsom, Graafland, \& Schijven, 2016). Little did I know that soon I would be bringing this tool into my qualitative research methods coursework as well.

\section{Methods}

\section{Participants and Setting}

The participants were 15 junior- and senior-level college students enrolled in a qualitative research seminar focusing on youth participatory action research (YPAR). As part of the course, the college students joined research teams with high school students to conduct YPAR-driven photovoice studies exploring experiences of trauma in urban schools and communities. This was the college students' first experience with qualitative research, and also working with high school students. 


\section{Theoretical Perspective}

The theoretical perspective underlying this study was constructivism. A critical aspect of constructivism is the participants' perceptions and meaning-making (Lincoln \& Guba, 2000). My college students were viewed as the experts of their experiences, and their constructions of knowledge about their experiences were of particular interest to me (Crotty, 1998).

\section{Intervention}

For the first four course sessions, college students learned the foundations of qualitative research, and specifically, YPAR, photovoice, and the SHOWeD method. We also spoke about research ethics, and engaged in in-depth reading and discussion about racial, economic, educational, and health equities and inequities pertaining to growing up in an urban community and attending public school. Sessions five and six provided different levels of scaffolded active learning opportunities for students to practice the SHOWeD method prior to working with the high school students as seen in Figure 3.



Fig. 3: Scaffolded levels of active learning opportunities to practice the SHOWeD method.

During session five, students participated in one practice photovoice session using the SHOWeD protocol with their college peers, and in the sixth session, students participated in a mixed reality simulation session in the Mursion classroom using the SHOWeD protocol with the student avatars.

For the MRS session, students worked in two-person teams with the student avatars for 10 minutes per team. During their 10-minute simulation, the teams were tasked with leading the five-student avatar class through a SHOWeD photovoice discussion based on a photo one of the student avatars took based on the topic of representing the idea of "balance" for a photovoice project. The students are hoping to inform the Principal about the various responsibilities in their lives, and to think about how to revise homework policies and support programs. My objectives for the college student teams were (1) to ensure that all students' voices were heard during the discussion; and (2) engage students in conversation about school improvement actions based on their conversation around each photo. I wanted to make sure that the students moved beyond simply describing the literal photos and discussed the deeper meaning behind the photo for the student avatars, and prompted the student avatars to envision community solutions based on the themes that emerged. The Interactor was prepared with reactions based on hits and misses for each objective (e.g., for the first objective, one student avatar would be silent unless directly prompted; and for the second objective, unless guided to thinking more deeply about the photo meaning and community solutions, the student avatars would simply derail and ask when class would be over or that they were getting bored). For full activity details and materials for the MRS activity, please refer to 
Appendix A. In sessions 7 through 15, college students convened with their high school coresearchers to actually carry out the photovoice project. During session 15 , the culminating activity was a photo gallery exhibit. School district leaders were invited to attend and engage in critical discussion with the students about their findings and recommendations.

\section{Data Collection}

Each week, students were required to post reflections in a discussion board in Blackboard, and respond to at least two of their peers. I analyzed the responses in discussion boards after four key sessions. In the first key course session, students reflected on general impressions after completing the first course meeting and learning the full details of the class. In the second key course session, college students reflected on impressions and asked questions based on class readings focused broadly on the qualitative research-driven interview processes. For the third and fourth sessions, students reflected on their experiences practicing the SHOWeD method with each other, and with the student avatars. Finally, I analyzed reflections about their learning processes included as part of their final papers for the course. As their professor, I kept a reflective journal across the course, and I include that in the data collection as well.

\section{Data Analysis}

Data sources were analyzed using Labov's (1972) fully formed narrative structure. It includes six components: (1) the abstract which summarizes the whole story; (2) the orientation which identifies the people, places, and activities of the story; (3) the complicating action which highlights a key event to the story and what happens next; (4) the evaluation which explains why this narrative is told and the "so what" message of the story; (5) the result or resolution which tells the reader what finally happened; and (6) the coda or end to the story. I read and re-read discussion boards, in addition to my own reflective journal, to identify the components of the narrative.

\section{Researcher Subjectivity}

Because of the nature of qualitative research, a researcher's subjectivity, or expression of their lived experience, is integral to the findings of a research study, and should therefore be explicitly identified (Brantlinger, Jimenez, Klingner, Pugach, \& Richardson, 2005). The process of examining one's subjectivity allows the researcher to identify the potential benefits and disadvantages that their experiences and beliefs potentially bring to a study.

I have worked in the field of Special Education for almost 20 years, in positions spanning intern, teaching assistant, teacher, policy advisor, graduate research assistant, and teacher educator. I have been using mixed reality simulations in my preservice teacher coursework for nearly four years. I have been a qualitative researcher working in the Special Education field, particularly in urban environments, for nearly 10 years. I believe that I know and understand how hard this work can be. However, prior to teaching this course, I had not worked with undergraduates learning about urban education and 
qualitative research methods for the first time before. I have not worked with novice qualitative researchers, learning for the first time, since I was one myself. This experience represented my first time teaching first-time qualitative researchers, and my first time preparing novice researchers to engage in youth participatory action research in an urban high school. I believed I was fully prepared, and could lean on my own memories as a novice learner in urban classrooms and qualitative research courses. I soon realized I had much to learn.

\title{
Findings
}

\begin{abstract}
Fifteen junior- and senior-level undergraduate students with no background in qualitative research enrolled in my Research Colloquium course about youth participatory action-driven qualitative research. The college students learned the foundations of conceptualizing, implementing, and analyzing a full qualitative study. Specifically, students learned how to carry out a youth participatory action research (YPAR) driven photovoice research project with the goal of creating research teams with students from a local high school to conduct YPAR studies on experiences of trauma in urban public schools and neighborhoods. The high school students were given disposable cameras and sent out into the school and community to take pictures that illuminated the topic at hand from their perspective. Pictures were developed by me, the professor, and then research teams comprising high school and college students came together to discuss the photos in groups of four to five. Using transcripts from audio-recorded conversations, and the photos themselves, the students worked together to create a photo gallery exhibit for school district leaders.
\end{abstract}

Everything started off smoothly until the college students began to immerse themselves in reading about qualitative research, and also about racial, educational, and economic inequities existing in urban school communities. The college students felt the weight, complexity, and importance of the work at hand. They became very worried.

\section{Orientation: How Hard Could This Be?}

In the early weeks of the semester, students were excited at the prospect of working with local high school students and learning about their lives. Many of them felt as though this would come naturally, since they love talking to their peers. How hard can qualitative research actually be? One student commented, "I spend a lot of time with my younger siblings and am very good at talking to them about their lives. This is great preparation for the work at hand in this class." As the professor, I felt cautiously optimistic, but knew there was much to learn in the coming weeks. 


\section{Complicating Action Clauses: It Is Mad Complicated!}

Within a few weeks of class, students had begun to learn the foundations of qualitative research, and many were stunned at the differences from the quantitative training they had been immersed in for the duration of their college careers thus far. When I checked the Blackboard discussion forum for their first week reading about how to conduct interviews as part of a qualitative process, I witnessed a stark change in tone from previous weeks. Students were becoming anxious. One student wrote:

When I first found out that a major component of this class was going to be effectively interviewing high school students for our research project I really thought I wouldn't have any problem. However, as I learn more I'm getting worried...

Another commented on his concern upon realizing just how far out of his quantitative comfort zone he had traveled: "It seems that the whole interview process is going to be difficult for most of us because many of us have never really engaged in such qualitative research where we can't use words like hypothesis!"

Finally, one student simply commented that simply working with the students might not be as easy as they had initially discussed with each other. She wrote, "Even with the preparation we do, it can seem daunting to be able to actually approach the students." The students were learning quickly about the complexity of qualitative interviewing, and also about the lives of the students we were about to meet. One student simply posted, "I am really concerned."

I reminded and reassured them in class that in the following week, they would have a practice opportunity with each other. The college students' homework that week beyond required readings was to take pictures that illuminated their experiences of being a college student. During the following week, they would have the opportunity to practice facilitating and participating in the SHOWeD discussion, and subsequently analyzing it, with each other. It was meant to be the safest environment for practice, and was strongly grounded in my own experiences from grad school. I learned how to interview by practicing interviewing my classmates. Naturally, this is how they would learn best too, right?

\section{Evaluation: My A-Ha! Moment}

After wrapping up class with my qualitative seminar students one afternoon, I was quickly shifting gears to teach a graduate-level special education course about reading and writing instruction and assessment. My graduate students would be practicing delivery of evidence-based instructional strategies for children with disabilities with the student avatars in MRS. I had an "A-Ha!" moment. I quickly scribbled a note to myself in my reflective journal:

My graduate students work with the student avatars as a scaffolded learning tool to practice with student avatars prior to working with living, breathing students out in the field. Why am I not bringing this technology into my qualitative research methods course where they also need practice prior to working with living breathing students? I speak freely about bringing in new technology to foster new and meaningful practice opportunities for my preservice teachers... 
why am I living in the past in my undergraduate course and clinging only to the ways that I learned in my own qualitative research methods courses?

\section{Result/Resolution: They Are the Experts of Their Lives}

I got to work developing a simulation that I could use with my qualitative research seminar students. For the simulation, each of the five student avatars "took a picture" illuminating their experience with stress at school in preparation to participate in a photovoice study with my college students. My college students would each have a 10-minute turn in the mixed reality classroom, and they would do so with a partner. I chose to do this because they would be working with at least one peer on their actual research teams with high school students. They would randomly be given one student avatar's photograph, and it was their task to practice the SHOWeD method with the mixed reality class. The other students sat with me in a horseshoe behind the student pair participating in the simulation, and took observational notes. In their 10 minutes, they were allowed to use an optional "remote control" feature to "pause" the simulation if they wanted, so they could seek advice and coaching from their peers and myself. After the simulation, we dedicated five to seven minutes for feedback and reflection. After class, students participated once again in discussion boards. Overall, students were receptive to the activity, and found that it helped ease some of their nerves, and also provided a sense of clarity about how the process might feel with their students, and some of the strategies that may work well, and others that might not. One student commented:

I thought it was a really cool experience to be able to interact with the Avatars, and especially to interact with them about pictures that they "took". It really helped me get a better feel about how to act and what to say with the high school students.

Many of the students reported feeling focused inward and only worrying about themselves prior to the simulation, but realized that some of the most powerful learning occurred from observing their peers:

I think the most helpful part wasn't even practicing myself, but seeing everyone else practice to get ideas on questions to ask, or the most effective way to develop rapport. We obviously all started the conversation a little differently and in turn, the conversations all went differently.

Furthermore, because each of the student pairs had a different picture, and it inevitably led down different rabbit holes of conversations with the student avatars, the college students were able to get a close examination of various pathways of interviewing high school students, and it helped them to begin to think about the importance and power of the wording they choose:

It was also helpful to see how the students reacted in an array of different situations. I kind of learned how to frame my questions like for example instead of saying, "Do you agree?" I should say, "What do you think about that?" so they have to say more than just yes or no and a real conversation can be facilitated.

I noticed that many students tried to develop scripts to support what they would say during interviews before coming to class that day. I notice that this happens a lot with my preservice teachers at first too. Perhaps the most important discovery and learning that took place was this: 
I learned I can't expect a certain response or level from the kids! I think that's what I took away - that we should not put limits and expectations on the students. We have to remain open, a reoccurring theme, in our interactions with them. At the end of the day they are the experts of their lives...

For students coming from strict quantitative and hard science backgrounds, the biggest learning curve was stepping away from hypotheses and highly controlled study designs and instead opening themselves to the places that their high school student coresearchers wanted to take them. Additionally, this exercise opened students up to each other, paving the way for collaborative relationships with each other. Many students reflected upon how it helped them to "come out of their shells" and bond:

This exercise also made me feel like I was more connected to my classmates. It's a class that's filled with bio majors. This exercise made me feel like we all bonded a little more as a class. Even just the way the room was set up was more welcoming to be "open" to one another and all inclusive. While watching everyone do their simulation, I felt like we were all connected more. There were a lot of moments where the simulated students would say funny things and we'd all laugh and I felt like that was the most I'd ever felt connected to the whole class, and not just a few classmates, it was nice.

\section{Coda: Remember to Not Forget How Hard This Is and Think Outside the Box}

In the month that followed the MRS experience, my students met and worked together with their high school coresearchers on photovoice research projects, analyzed the data together with them, and held a photo gallery exhibit attended by district school leaders, including the superintendent. One student reflected it quite well:

This course resulted in an outcome I did not expect in September. Until this course, I hadn't heard of qualitative research, and upon hearing about it, I didn't understand its significance. After intense readings on youth participatory action research, photovoice, and after learning many theories, I quickly learned about qualitative research. Slowly I began to understand its importance and great implications. It wasn't until I met the [high school] students, that I realized how big of an impact we could actually make in our local communities. What we learned in the readings and the simulations was now finally reality. During our first meeting with the students, we talked about important social issues like race, incarceration, poverty, education, etc. We provided an environment for our participants to openly voice their concerns, and at the end of the discussion, we handed them all cameras and told them to take pictures of what social issues they thought were represented in a picture. A week later, we received the photos from the students, and what we saw was very unexpected but it was reality for our participants. This was when we, as researchers, began to understand the lives of our participants.

Refer to Figures 4, 5, and 6 for examples of final photovoice exhibit examples. Each of the photos includes a caption represented by high school coresearcher voices to illuminate the experiences and perspectives behind the photos. While it is beyond the parameters of this paper to fully discuss the photo gallery exhibit experience, you may visit https://tinyurl.com/y9oab5fn for more information. 
Kristin M. Murphy

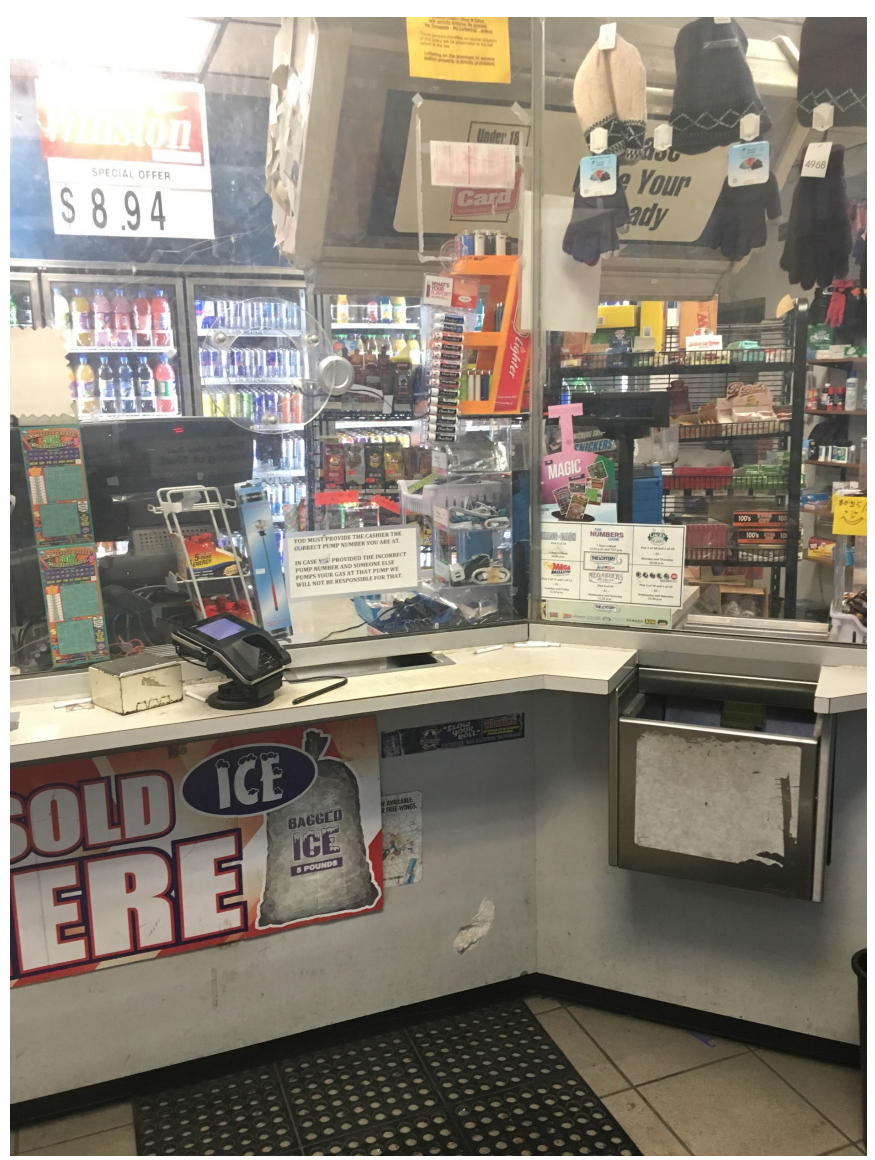

Fig. 4. You can look but you better not touch: "Like stick your hand through and take it out. They did that because of all the gunshots and stuff that was happening. They got scared so they guarded it up, yeah. So you walk in the back and they pat you and everything through here."

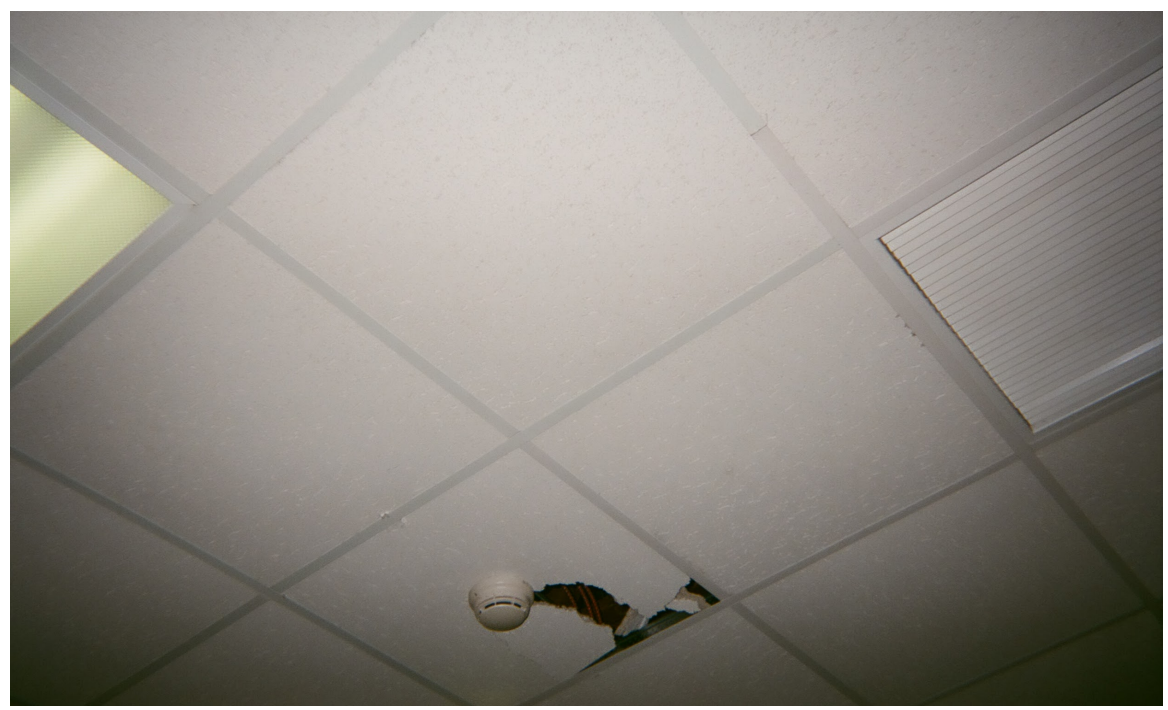

Fig. 5: Black hole: "Nobody has any money to fix it. The only thing that they fix is the gym. They haven't fixed anything else but the gym." 


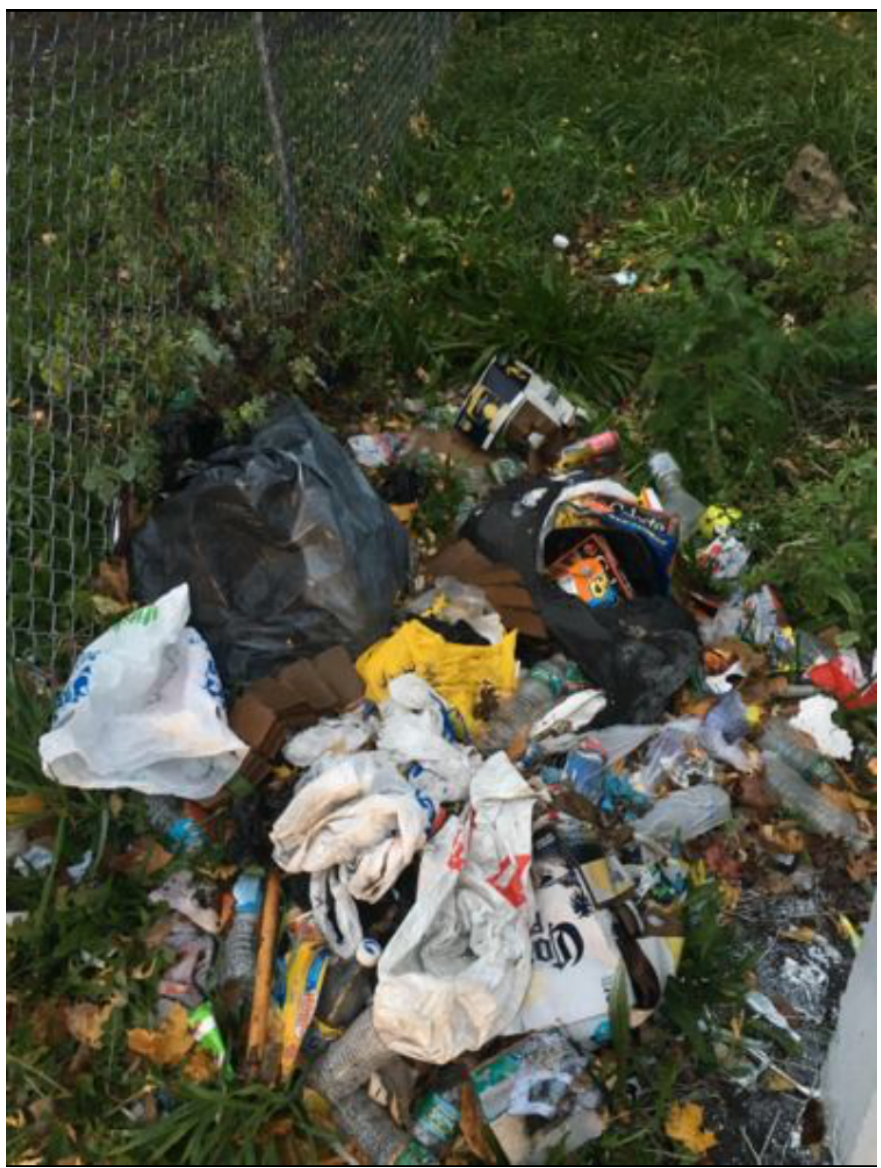

Fig. 6: The local dump: "Nobody bothers to pick them up. Um, this is in front of people's houses. Yeah, just a regular day."

Beyond the photo gallery exhibit and final papers, it was clear that much more happened in this immersive community-based learning class about qualitative research methods comprising reluctant quantitative research enthusiasts:

Overall, this experience really opened my mind and I feel that as a student pursuing a career in medicine, this research project was a crucial milestone in my development. I can relate this all back to the barriers presented in the healthcare field for people that are from low socioeconomic backgrounds, especially those who face street trauma growing up. Towards the end of this course, we presented our findings to the superintendent. For once, I felt as though my research team and I have actually made an impact with the work we've done in college. I'm personally so moved by this project.

Another student reflected:

This research experience exposed me to an entirely new method of research, one that values human experience over statistics. As a science major, I have worked for years to develop skills that would make me successful in quantitative research: removing bias from experiments, planning and controlling all parts of data collection, and never developing a relationship with the subjects. These guidelines make sense in a scientific environment when you are trying to find 
underlying biological or chemical mechanisms of processes; however, I realize now that they don't make sense when the research is aimed at improving human experience and institutional policy. Qualitative research has the unique power of being engaging because the stories of participants are often so moving and relatable. I learned that listening to these stories is the best way to truly understand one's experience, and by understanding it, you can provide better solutions to some of society's greater problems.

At the end of this experience, I had so much to reflect on as the professor. I learned several important lessons. I think that I know how hard this is - by this, I mean working with high school students in urban school communities, and I also mean conceptualizing and carrying out a qualitative research study. And this is true. I do know how hard it is, but, the notion of what is hard has changed and evolved in my mind the longer that I am in this field, and as my own roles and responsibilities shift. It was important for me to spend the semester working with college students who had no prior experience to remember just how complex those first steps are in working with high school students, and dipping your toes into qualitative research.

Furthermore, I realized that I was operating in compartmentalized ways in my own teaching. I was energized and excited about taking advantage of new technology offered by mixed reality simulations to support my preservice teaching students in ways I could not have imagined when I was training to become a teacher. But, when I had the opportunity to teach students their very first qualitative methods course, I immediately resorted to the methods I was exposed to as a student myself. The jump from roleplaying with fellow college students to mentoring high school coresearchers in the field was a large leap. Providing a scaffolded risk-free opportunity for practice with the avatars in the mixed reality environment was an ideal middle ground on their pathway to learning.

My "Ah Ha!" moment was a powerful one for me, to take a tool that was working well for me in one area of my teaching, and reconceptualize it to enhance and foster improved active learning opportunities in another area. I need to continue to think outside the box of what I know. I need to continue to actively take the time to listen to my students, and myself. I need to continue to explore the power that lies in immersive community-based learning and challenge my own notions of how to teach and learn.

\section{Concluding Thoughts}

Conducting qualitative research is not easy. Learning to understand qualitative research, and how to carry it out, takes time. The act of carrying out YPAR adds a highly complex layer due to the sensitive nature of the topics explored, and the mentorship of child and adolescent coresearchers. However, the rewards for pursuing this research are abundant. In teaching this course, I learned that teaching YPAR and learning how to conduct YPAR benefits from thorough planning and varied modalities for acquiring confidence and mastery, in addition to keeping an open mind and willingness to be flexible along the way. Novice qualitative researchers can only benefit from varied and multiple opportunities for practice, and as their mentors and teachers, we must continually reflect, practice, and listen in order to foster meaningful active learning opportunities for our students and ourselves. MRS offered a powerful 
scaffolded step in my students' journey to learning and knowing how to be thoughtful qualitative researchers. The body of literature exploring the application of MRS as a tool for active learning is still young. I encourage you to think about how learning with avatars may serve as a valuable scaffold for you and your students on their pathway to experiences in the real world. I look forward to learning from you.

\section{Acknowledgment}

The project and research reported in this publication were supported by the UMass Center for Clinical and Translational Science UL1TR001453, the UMass Boston Joseph P. Healey Research Grant Program, and the UMass Boston Civic Engagement Scholars Initiative. The content is solely the responsibility of the author and does not necessarily represent the official views of UMass Boston or the UMass Center for Clinical and Translational Science.

\section{References}

Barsom, E. Z., Graafland, M., \& Schijven, M. P. (2016). Systematic review on the effectiveness of augmented reality applications in medical training. Surgical Endoscopy, 30(10), 4174-4183.

Brantlinger, E., Jimenez, R., Klingner, J., Pugach, M., \& Richardson, V. (2005). Qualitative studies in special education. Exceptional Children, 71, 195-207.

Brunson, R. K., \& Miller, J. (2007). Young black men and urban policing in the United States.

British Journal of Criminology, 46, 613-640.

Crotty, M. (2003). The foundations of social research. London: SAGE Publications.

Ginwright, S. A. (2007). Black youth activism and the role of critical social capital in Black community organizations. American Behavioral Scientist, 51, 403-418.

Gubrium, J., \& Holstein, J. (Eds.). (2002). Handbook of interviewing: Context and method. Thousand Oaks, CA: Sage.

Hayes, A. T., Straub, C. L., Dieker, L. A., Hughes, C. E., \& Hynes, M. C. (2013). Ludic learning: Exploration of TLE TeachLivE ${ }^{\mathrm{TM}}$ and effective teacher training. International Journal of Gaming and Computer-Mediated Simulations (IJGCMS), 5(2), 20--33.

Hughes, C. E., Nagendran, A., Dieker, L. A., Hynes, M. C., \& Welch, G. C. (2015). Applications of avatar mediated interaction to teaching, training, job skills, and wellness. In G. Brunnett et al. (Eds.), Virtual realities (pp. 133-146). Switzerland: Springer International Publishing.

Labov, W. (1972). Language in the inner city. Philadelphia, PA: University of Pennsylvania Press.

Latz, A. O. (2017). Photovoice research in education and beyond: A practical guide from theory to exhibition. New York, NY: Taylor \& Francis. 
Latz, A. O., Phelps-Ward, R., Royer, D., \& Peters, T. (2016). Photovoice as methodology, pedagogy, and partnership-building tool: A graduate and community college student collaboration. Journal of Public Scholarship in Higher Education, 6, 124-142.

Lincoln, Y.S., \& Guba, E.G. (2000). Paradigmatic controversies, contradictions and emerging confluences. In N.K. Denzin \& Y.S. Lincoln (Eds.), Handbook qualitative research (2nd ed., pp. 105-117). Thousand Oaks, CA: Sage.

Mirra, N., Garcia, A., \& Morrell, E. (2015). Doing youth participatory action research: Transforming inquiry with researchers, educators, and students. New York, NY: Routledge.

Murphy, K. M., Cash, J., \& Kellinger, J. J. (2018). Learning with avatars: Exploring mixed reality simulations for next-generation teaching and learning. In Handbook of research on pedagogical models for next-generation teaching and learning (pp. 1-20). IGI Global.

Roulston, K., deMarrais, K., \& Lewis, J. B. (2003). Learning to interview in the social sciences. Qualitative Inquiry, 9, 643-668.

Storey, V. J., \& Cox, T. D. (2015). Utilizing mixed reality to building educational leadership capacity: The development and application of virtual simulations. Journal of Education and Human Development, 4, 41-49.

Straub, C., Dieker, L., Hynes, M., \& Hughes, C. (2014). Using virtual rehearsal in TLE TeachLivETM mixed reality classroom simulator to determine the effects on the performance of mathematics teachers. 2014 TeachLive National Research Project: Year 1 Findings.

Wang, C. C. (2006). Youth participation in photovoice as a strategy for community change. Journal of Community Practice, 14(1-2), 147-161.

Wang, C., \& Burris, M. A. (1994). Empowerment through photo novella: Portraits of participation. Health Education Quarterly, 21(2), 171-186.

Wang, C., \& Burris, M. A. (1997). Photovoice: Concept, methodology, and use for participatory needs assessment. Health Education \& Behavior, 24(3), 369-387.

Watts, M. N. C., \& Liamputtong, P. (2013). Sensitive research and vulnerable participants: Accessing and conducting research with Australian teenage mothers in Greater Melbourne, Australia. GSTF International Journal of Nursing and Health Care, 1, 192-198. 


\section{Appendix A}

\section{Mixed Reality Simulation Materials}

\section{Challenge for college students:}

Your middle school coresearchers have each brought in one picture representing the idea of "balance" for the photovoice project they're working on with you in class! The students are hoping to inform the Principal about the various responsibilities in their lives, and to use this YPAR project to think about how to revise homework policies and support programs. In this 10-minute simulation, you will be randomly assigned one of the photos below taken by the student avatars, and lead the class through the SHOWeD discussion protocol with this photo.

\section{College student objectives for the simulation (10 minutes):}

1) Establish rapport with students.

2) Lead discussion of "what do you see" in this picture using the SHOWeD discussion protocol.

3) Make sure to hear from all students and engage in asking open-ended questions!

\section{Tools}

You will work with one teammate. You may employ "remote-control teaching" in the mixed reality classroom. If you are stuck or have a question, simply say, "Pause classroom," for the opportunity to engage in a coaching and feedback session with your peers. After your session, we will engage in a coaching and feedback debrief. After the debrief, you will complete a brief reflection independently.

\section{$\underline{\text { Student avatar photos }}$}

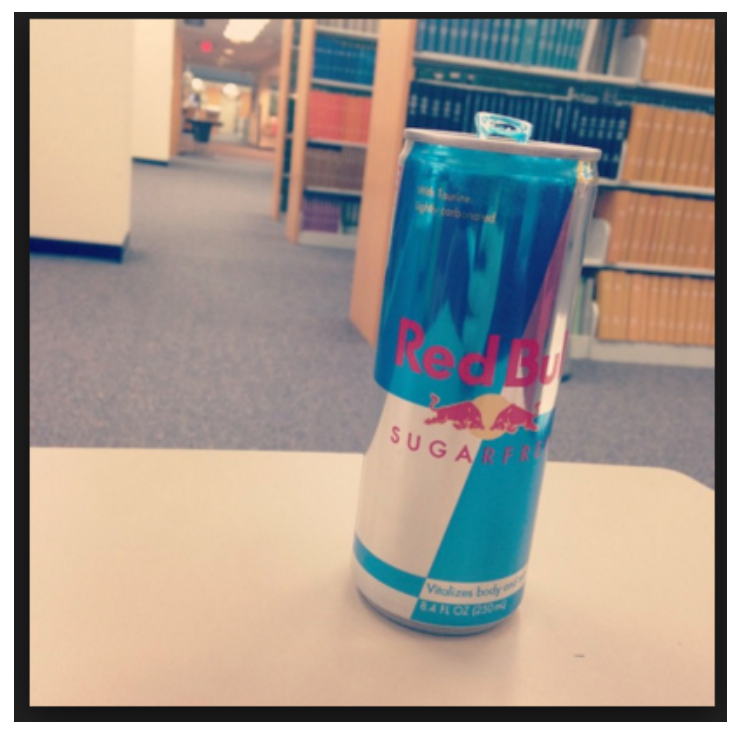

Savannah \#1: Can of red bull in media center.



Savannah \#2: Chewed up pen cap. 




Dev \#1: Blank screen on computer.

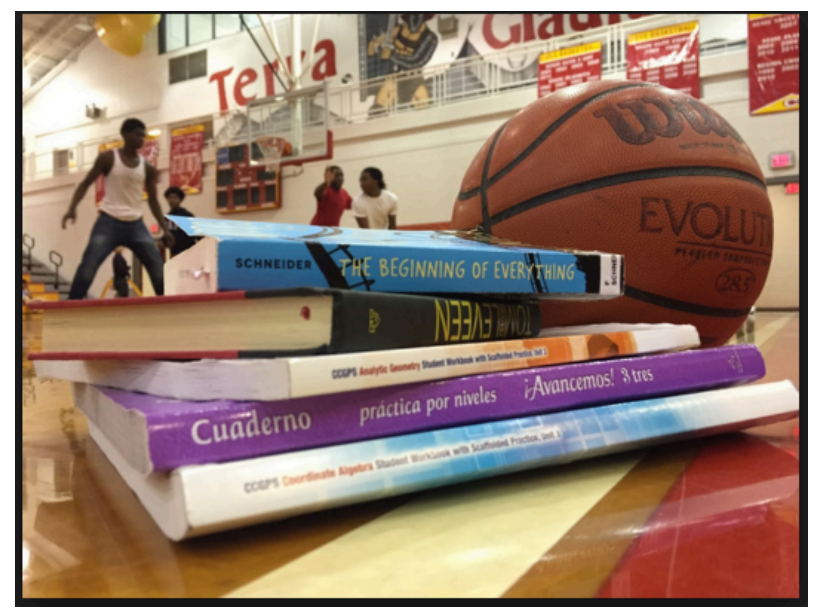

Ethan \#1: Balancing academics and basketball practice.

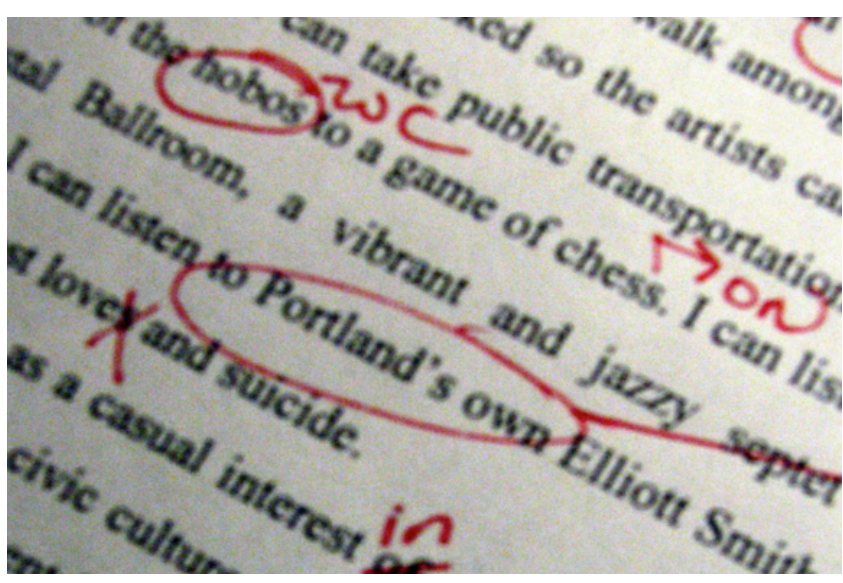

Ava \#1: Close-up of red mark-ups from teacher on an assignment.

202 | LEARNing Landscapes | Spring 2019, Vol. 12

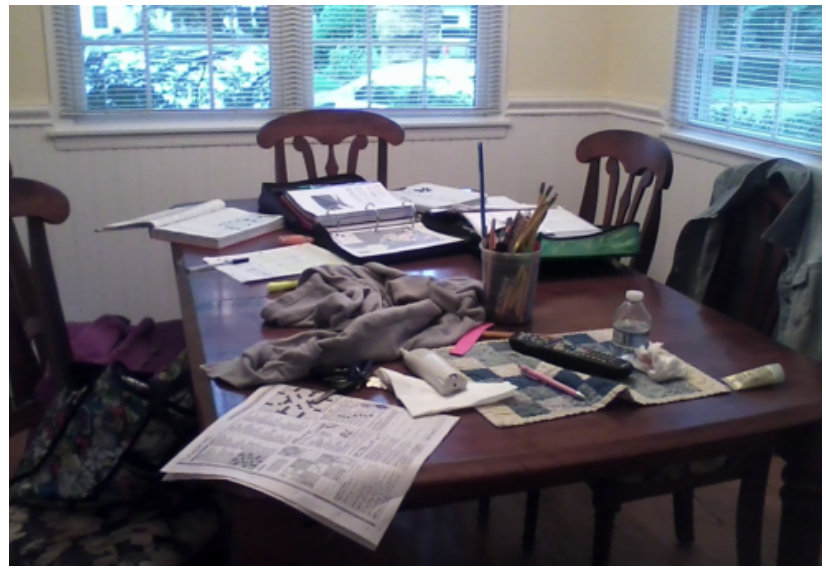

Jasmine \#1: Crowded table with everyone's homework (siblings, cousins).

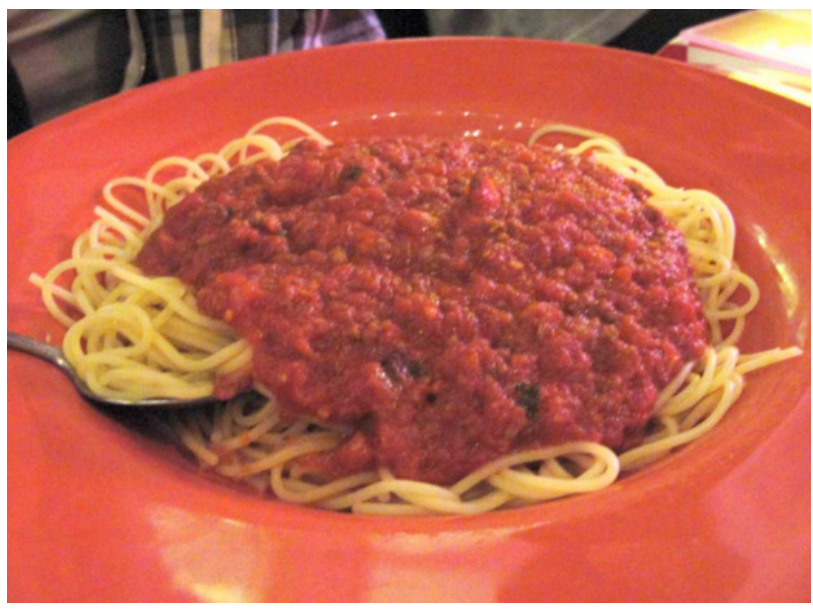

Ethan \#2: Pasta dinner with teammates.

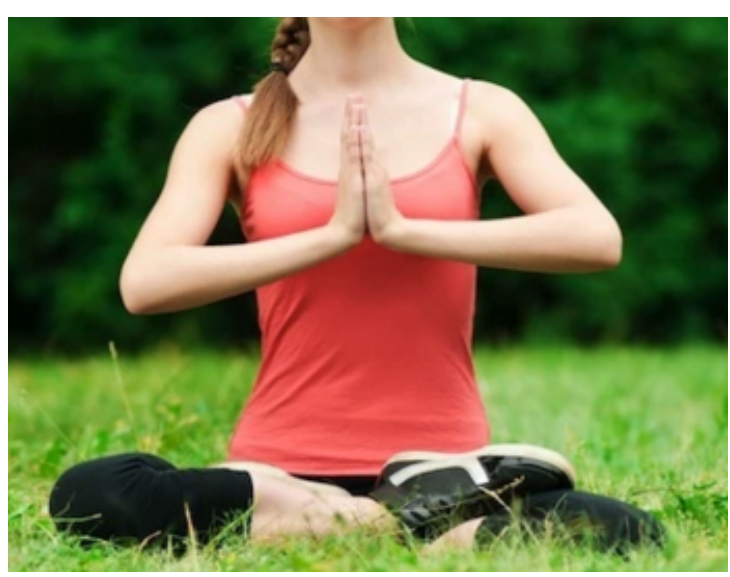

Ava $\# 2$ : Photo of friend doing yoga. 


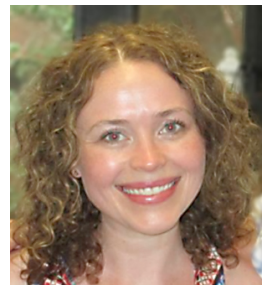

Kristin Murphy, PhD, is an Assistant Professor of Special Education at the University of Massachusetts Boston, in Boston. Dr. Murphy has served in various special education teaching, research, and policy positions for 15 years. Her research primarily focuses on the design of pre- and in-service professional learning opportunities to support teachers and school leaders in urban school settings, including exploring mixed reality simulations as an active learning tool for teachers and K-12 students. She holds a master's degree from Harvard University and a PhD from the University of Florida. 